\title{
EL LLAMADO NEPTUNO (RÍO?) DE LA COLECCIÓN DEL CARPIO Y SU PROBLEMÁTICA IDENTIFICACIÓN CON UNA OBRA ATRIBUIDA A BERNINI, EN ARANJUEZ
}

\author{
POR
}

MARGARITA M. ESTELLA

\begin{abstract}
La figura del Río (?) estudiada se encuentra en el Jardín del Príncipe de Aranjuez. Se propone su identificación con el Neptuno procedente de la colección del Marqués del Carpio comprado por Felipe V a la Duquesa de Alba por una serie de documentos que se analizan como, entre otros, su descripción en la Almoneda de la colección que lo presenta echado. Al no aparecer bajo su nombre en los Inventarios de los bienes que integraban la colección realizados antes de su envío a España se sugiere que puede ser uno de los ríos que conformaron la réplica de la fuente de la Plaza Navona cuya dirección encomendó el Marqués del Carpio al propio Bernini.
\end{abstract}

Palabras clave: Escultura. Barroco. Bernini. Río. Neptuno. Aranjuez. Jardín del Príncipe

The statue representing a River studied here is in the Prince's Garden, Aranjuez. Based on a series of documents, among them the description of a reclining figure in the Marqués del Carpio auction, the author proposes its identification with the Neptune from the Carpio collection, later purchased by Felipe V from the Duchess of Alba. As the work is not specifically named in the Carpio inventories drawn up in Italy prior to shipment to Spain, it is suggested that it may be one of the river figures from the replica of the Piazza Navona fountain the direction of which was commissioned by Carpio from Bernini himself.

Key words: Sculpture. Barroque. Bernini. River. Neptuno. Aranjuez. Prince's Garden.

Los jardines de Aranjuez duermen su pasada gloria que el tiempo inexorable sumió en el olvido al pasar el tiempo pero aun guardan entre sus frondosas avenidas restos artísticos de aquel esplendor.

Su proximidad a Madrid, ciudad de duro clima, los convirtió en el lugar ideal para el descanso y solaz de la Corte que otros Sitios reales suburbanos, como el Pardo, la Casa de Campo o el Buen Retiro no podían proporcionar por carecer de las condiciones naturales de las que gozaba Aranjuez. Como un oasis, en la seca meseta castellana, ofrecían el verdor y frescura de su vegetación prácticamente en todas las estaciones del año, recostados a las orillas del Tajo que templaba la aspereza climática de su entorno.

Concebidos desde su primera reordenación por Juan Bautista de Toledo como Jardines arqueológicos, a ellos fueron a parar un sinnúmero de esculturas italitanas encargadas o regaladas para su ornamentación.Las noticias documentales sobre este tema aparecen dispersas en la 
bibliografía artística y no es fácil concebir su primitiva ordenación debido a que el perdido proyecto o programa que sin duda concibió Toledo fue alterado al pasar los años.

Se ha estudiado con cuidado en diversas ocasiones su estructura arquitectónica que en el Jardín de la Isla conserva la decidida en tiempos de Felipe IV en tanto que en el resto de sus jardines se atiene en líneas generales a su organización dieciochesca.

No obstante, como ya se advirtió hace varios años, su rica, variada e importante colección escultórica prácticamente permanecía anónima pues se admiraba bajo el prisma de ser complemento decorativo de la maravilla paisajística de su espléndida naturaleza. Los árboles, las flores, los pájaros y el murmullo del agua adormecían el sentido crítico del espectador que apenas percibía la belleza artística de, por ejemplo, la Venus secándose el cabello o de Diana seguida por sus perros, verdaderos actores de este teatro, aunque natural, artificioso.

Terminada la representación por el cambio histórico, las figuras representativas del espectáculo aparecen desarraigadas de su contexto y hoy en día al pasear por los jardines sorprenden al visitante en variados parajes sin el orden lógico de lo que en su tiempo significaron.

Hace años se inició el estudio de algunas de ellas con el objetivo de determinar la exacta filiación artística de las más significativas que además de determinar sus caracteres específicos facilitara la comprensión del programa que presidió la ordenación de los conjuntos escultóricos. Desde el primer momento se advirtió la dificil tarea debido a que en muchos casos se destinaron a Aranjuez, de forma indiscriminada, grupos de esculturas no relacionadas entre sí.

Así por ejemplo, a juzgar por la fidedigna aunque incompleta descripción de Cassiano del Pozzo (1625) que puede considerarse como la que mejor responde a la ordenación de la época de Felipe II , al conjunto de esculturas que se destinaron al decoro del Jardín de la Isla se añadió, en el reinado siguiente, el procedente del legado Mansfeld destinado a otro lugar.

La reorganización escultórica llevada a cabo en el reinado de Felipe IV, bien reflejada en la descripción de Alvarez de Colmenar (1707), tampoco tuvo en cuenta la idoneidad de los grupos escultóricos que la integraron y quizás por ello los Borbones del siglo xviII decidieron la fundación «ex novo» de los Jardines de San Ildefonso en los parajes de La Granja, perfectamente programados. Aunque en estos años no se olvidaron de los de Aranjuez, y de hecho se llevó a cabo la terminación de la estructura del Parterre y la nueva ordenación del Jardín del Príncipe que entonces adquiere su fisionomía, otra vez sus jardines reciben de forma indiscriminada esculturas destinadas en principio a otro lugar o sin ubicación conocida.

Este preámbulo pretende explicar por qué tantas esculturas, algunas de gran valor, permanecen inéditas solo conocidas algunas de forma indirecta, como las que constituyeron la famosa fuente debida al Algardi, en realidad compuesta de los monumentales «morillos»o «guarda-fuegos», capifuochi en el léxico italiano, destinados en principio al Alcázar.

En estos años se ha ido desvelando la identidad de algunas de ellas, una a una en sucesivos trabajos a los que continúa el presente como parte de un estudio en conjunto que podrá llevarse a cabo cuando se conozca la identidad estilística y procedencia de al menos un número importante de estas esculturas ${ }^{1}$.

\footnotetext{
' Estella Marcos, Margarita M., «Sobre las esculturas del Jardín de la Isla en Aranjuez», Velázquez y el Arte de su tiempo. V Jornadas de Arte. CSIC, Madrid, 1991, 333-348. Idem, «La Venus del Jardín de la Isla», Adan y Eva en Aranjuez.Sobre la escultura de la Casa de Austria. Madrid, Museo del Prado, 1992, 71-88. Idem, «Temas mitológicos de los jardines de los siglos xvı y xvII. Obras inéditas o poco divulgadas de Camillani, Regio, Algardi y anónimas», La Visión del Mundo Clásico en el Arte Español. VI Jornadas de Arte. CSIC, Madrid, 1993, 67-80. Idem, «Decoración escultórica de los Jardines Reales del siglo xvi al xvir según el texto de Álvarez de Colmenar (1707), Struggle for Synthesis. The total work of art in the 17th and $18^{\text {th }}$ centuries. Braga, june, 1996, 451-461. Idem, «Las Cuentas del Tesorero Roger Patié y otros documentos. Esculturas y Antigüedades de María de Hungría y los Jardines de Aranjuez, Archivo Español de Arte (AEA), 2001, 239-256.
}

AEA, LXXV, 2002, 298, pp. 117 a 128 


\section{La Fuente del «Quattro dei Molo» y envío a España de las figuras de sus Ríos}

Hace años se recogieron una serie de noticias documentales sobre el envío de fuentes italianas destinadas a los jardines de Aranjuez. Entre ellas se localizó la referente al envio tardío de las cuatro figuras de los ríos mayores del Mundo, el Eufrates también llamado Argenteo o Plata ,el Tigris, el Ganges y el Nilo que decoraban la famosa Fontana dei quattro dei Molo en el muelle grande del Puerto de Nápoles. Encargada en tiempos del Virrey Perafán de Ribera, Duque de Alcalá, el año de 1559 se realizó bajo la dirección del ingeniero Castaldi por los escultores Anibal Caccavello y Michele d'Auria. Estas figuras del tamaño del natural se interpretaron como viejos barbudos semiacurrucados vertiendo agua de unas urnas que sujetaban entre sus piernas.

Se supo también que las esculturas de estos cuatro ríos se enviaron por el Virrey Pedro Antonio de Aragón a España para los jardines de Aranjuez en 1670. Los historiadores italianos intentaron localizarlas después de la publicación de estas noticias pero la carta que Rafael de Altamira dirige a Benedeto Croce, colaborador de Napoli Nobilissima, la revista que las había dado a conocer, informaba que no se habían localizado en Aranjuez pero que Conca describía en la Casa de Campo cuatro esculturas en mármol con urnas que podrían ser las buscadas ${ }^{2}$.

Se comprobó que la noticia procedía de Ponz al citarlas en el pasaje donde está colocado el caballo hay, en los ángulos de un cuadro del jardín, cuatro estatuas de mármol del tamaño del natural, en actitud de vaciar urnas de agua, que es significación de ríos; están hechos con mucha inteligencia y grandioso carácter según el antiguo de la escuela florentina, que sí podían corresponderse perfectamente con las realizadas en Nápoles en 1559. No obstante, en la bibliografía consultada sobre este sitio real no se mencionan ni antes ni después de las publicaciones citadas, es decir, la de Ponz y la de Conca, que le sigue literalmente.

Se insistió en su búsqueda pero efectivamente no se localizaron sus restos ni en los dispersos de la Casa de Campo ni en el jardín de la Isla. También se revisaron las últimas ediciones del Viaje de España y la de 1791, en la que Ponz, al hablar de la reorganización del Jardín del Príncipe de Aranjuez aclaró que, en un lugar próximo a la Fuente de Apolo, junto al gran estanque, se ha colocado en el suelo como cabeza de manantial, una estatua alegórica que representa una fuente o rio, y es de la colección de San Ildefonso; obra de mucho mérito aunque no de remota antigüedad, sino del tiempo que renacieron las artes, a fines del siglo xV o principios del XVI, según yo pensé; tiene mucho del estilo de Buonarroti, descripción que recoge casi literalmente Sebastián Conca el año de $1793^{3}$.

La cita parecía podía también referirse a una de las figuras de los ríos de la Fuente napolitana mencionada no solo por su iconografía sino por su estilo en juicio de Ponz, en general muy ajustado en las obras que describe. Ello sugería, siempre en hipótesis, que quizás había habido un trasvase de esculturas de la Casa de Campo a Aranjuez en los años trascurridos desde la primera edición de su obra de 1772 hasta el año de 1791.

\footnotetext{
2 Starace, Francesco, «Angelo Landi, Nicola Antonio Stigliola e il disegno di una fontana nel porto de Napoli», Napoli

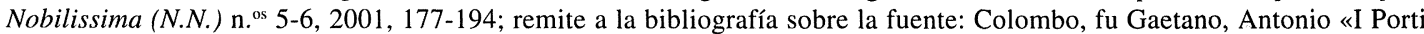
e Gli Arsenali deNapoli», III, N.N. 1894, 51-92, que trascribe el documento de Capasso, B., «La Fontana dei Quattro dei Molo», Archivio Storico per le provincie napoletane, V. 1880. 158-194: "statue de grandezza al natural che sotto l'aspetti di vecchi con lunghe barbe rappresentavano i quattro principali fiumi del mondo, Eufrates, Tigri, Gange e Nilo e cuevi e quasi accovacciati dalle urne che avevano fra le gambe». Salazar, Lorenzo, «Documenti inediti intorno ai artisti napoletani del secolo XVII", N.N., IV, 1895, 185-186. Se paga a un escultor y a un carpintero el año de 1670 por orden del Virrey Pedro Antonio de Aragón por hacer las cajas en las que se enviaban a España las cuatro figuras de los ríos de la Fuente mencionada. «Notizie e Osservazione», N.N. VI, 1897, 109-110, no recogida por Starace: trascribe la carta de Altamira a Benedetto Crocce.

${ }^{3}$ Ponz, Antonio, Viaje de España (ed. 1772), Madrid, Aguilar, 1947, 559. Idem, Viaje. Ed. 1791 recogida en El Real Sitio de Aranjuez y el Arte cortesano del siglo xvilI, Aranjuez, 1987, 116-117. Conca, Don Antonio, Descripción odepórica della Spagna. Parma, 1793, I, 158, Casa de Campo, y 304, Aranjuez.
} 
No obstante y a partir de este último año no se han encontrado referencias a una figura de río en Aranjuez y sólo se ha comprobado que desde la publicación de Alvarez de Quindós, que describió con minuciosidad sus jardines en 1804, fecha muy próxima a las anteriores, aparece mencionada otra figura en el mismo lugar que Ponz situara la figura alegórica del río. El texto explica que emboscada y oculta sobre la tierra entre árboles y arbustos se encuentra una estatua de mucho mérito por su escultura; ella es antigua y lo mejor que hay en este jardin: representa a Neptuno, dios de las aguas, recostado y agrupado con un caballo marino; está colocada con mucha propiedad, formando sus aguas un pequeño arroyo (fig. 1) ${ }^{4}$.

Surgió la duda sobre la posible sustitución de la figura del río descrita por Ponz por la de un Neptuno por lo que se orientó la investigación en otra dirección pues por los datos dados no parecía que la conservada, aún teniendo en cuenta la noticia del ilustre Abate, pudiera ser uno de los cuatro ríos de la fuente napolitana que por lo que se dirá hasta ahora no se han localizado.

\section{La Fuente Navona de la colección del Marqués del Carpio}

Ponz había dicho que la figura del río descrito en su edición de 1791 procedía de las colecciones de San Ildefonso y curiosamente en la primera edición de su Viaje de 1781 mencionó un Neptuno con su tridente sin determinar la materia en la que estaba realizado ni referirse a él al describir el río de Aranjuez, entre las esculturas que se conservaban en la Galería del Trascuarto, depósito de algunas de la colección de la Reina Cristina de Suecia adquirida en parte por Felipe V, llegadas a este palacio en 1725 .

Un artículo de Miguel Angel Elvira estudió las antigüedades romanas que se conservaban en el Jardín del Principe de Aranjuez sin aludir a este Neptuno pero mencionó la Lista de las Estatuas y bustos que existen en el Rl Sitio de Aranjuz llevadas por Odn de S.M. del Sitio de Sn Yldefonso, anexo al Inventario de los bienes de Carlos III (II, 1789) en la que sí se menciona Un Neptuno del tamaño del natural de mármol blanco, con su cabeza de caballo y tridente que está recostado ${ }^{5}$.

Todo parecía indicar que el Neptuno descrito por Quindós se había enviado a Aranjuez hacia el año de 1789 pero las noticias no aclaraban si había sustituido al río descrito por Ponz o en realidad se trataba de un mero cambio de denominación, fácil en dos composiciones que pueden confundirse como más adelante se aclarará.

Se siguió el estudio en esta dirección por ver si al revisar los antecedentes de la pieza enviada desde San Ildefonso proporcionaban otros datos y en un magnífico estudio de Beatrice Cacciotti se localizaron los que en parte aclaran el problema pero desde otro punto de vista lo complican.

Según esta autora Felipe V compró algunas esculturas de gran calidad a la Duquesa de Alba, heredera del famoso Marqués del Carpio, el conocido coleccionista Embajador de España en Roma y después Virrey de Nápoles. La lista de las obras compradas a la Duquesa el año de 1746, anexo al Inventario de Felipe V de las que el Rey tiene en S. Ildef.o menciona un Neptuno al parecer de mármol pues se relaciona entre otras de este material. El estudio localiza varias

\footnotetext{
${ }^{4}$ Álvarez de Quindós y Baena, Juan Antonio, Descripción histórica del Real Bosque y Casa de Aranjuez. Ed. facsímil. 1804, 304-306. Instalado ahora en la Fuente de los Pabellones. Vid. nota 9: Añón.

${ }^{5}$ Ponz, cit. en 3. Viaje. 1. ${ }^{a}$ ed. de 1781. T. X. Carta V, 885-904, cit. a Neptuno en 892. Elvira, Miguel Ángel, «Las Antigüedades romanas en el Jardín del Príncipe y la Casa del Labrador», Reales Sitios, XXXI, 122, 1994, 57-65. Inventarios Reales: Testamentaría del rey Carlos III, 1789-1790. Transcripción por F. Fernández Miranda, Madrid, 1989, II, 54 .
}

$A E A$, LXXV, 2002, 298, pp. 117 a 128 
de estas esculturas pero del Neptuno se dice que pudiera ser la representación de este personaje conservada en San Ildefonso, identificada con la que se exhibe en el Museo del Prado, en pie.

En realidad, como se ha visto en el anexo al Inventario de Carlos III y en la obra de Alvarez Quindós, el Neptuno procedente de San Ildefonso llevado a Aranjuez estaba recostado pero lo que no se sabía era si se correspondía con el Neptuno con su tridente descrito por Ponz en San Ildefonso y sí, a su vez, fue el comprado a la Duquesa de Alba en 1746. El detalle del tridente que se menciona también en la figura enviada a Aranjuez y las circunstancias expuestas sugieren que fuese la misma escultura que se compra a la Duquesa, como se dirá.

Esta suposición presentaba el escollo de la mención que se hace en el mismo Inventario de Carlos III de otro Neptuno antiguo de ocho pies y quarto de alto que parece ser, según explica Beatrice Cacciotti, se piensa que es el conservado en el Prado aunque ya la autora recuerda que Winckelmann le situaba aún en Roma el año de 1764, es decir después de la compra de las esculturas a la Duquesa de Alba y que en todo caso si como dice Blanco se descubrió ya a mediados del siglo XVIII no puede pertenecer a la colección del Marqués del Carpio, todo lo cual parecen confirmar otros documentos.

En efecto, en la relación mencionada del año de 1746 no se especificaba la postura del Neptuno pero en la Almoneda de los Bienes del Marqués del Carpio realizada en Madrid en 1689, concretamente en el Inventario que precede a la venta se describe Un Neptuno echado de marmol blanco que estaba en el Jardín de Sn Joachin y que fue tasado en 3.300 reales que no se vendió pues aparece inventariado con posterioridad a esta fecha, ahora como Neptuno de mármol blanco sin especificar su postura pero situado en el mismo lugar y valorado en la misma cantidad de 3.300 reales como puede leerse en documentos del Archivo de la Casa de Alba, como la Memoria de las pinturas y alajas questan de la testamentaria del Ex.mo S.r del Carpio.. en el Jardin de Sn Joachin asi de las que avia en el tiempo de su fallecimiento como las que an quedado del Almoneda asta fin de septiembre de este año de mill setecientos y seis, fecha en la que se inician probablemente los trámites por parte de la Corona para la compra de parte de la colección. Es decir que todos los datos expuestos apuntan a que la escultura enviada a Aranjuez sea la que se compra a la Duquesa de Alba ${ }^{6}$.

Para completar la Investigación se consultaron los Inventarios del Marqués del Carpio redactados en Italia antes de la llegada de la colección a España, el de 1682 publicado por Beatrice Cacciotti y los manuscritos de 1683 y 1687 que se conservan en el Escorial y se advirtió que en ellos no aparece descrita ninguna escultura que representara Neptuno y que por los datos que proporciona la autora citada no parece que se reprodujera en el álbum de diseños de la colección, conservado en la Sociedad de Anticuarios de Londres.

Parecía que el camino se cerraba y que la teoría expuesta se venía abajo pero entonces se advirtió que lo que sí destacan los Inventarios del Carpio es el envio a Madrid, entre los numerosos bienes de la colección, de una magnífica fuente de mármol, réplica de la realizada por el Bernini para la Plaza Navona de Roma, y que la copia fue dirigida por este mismo artista según se lee literalmente en la inscripción que aparecía en una de las losas enviadas a España que decía: Siendo Embajador de Inocencio XI Summo Pontífice por la magestad de Carlos

' Cacciotti, Beatrice, «La collezione del VII Marqués del Carpio tra Roma e Madrid», Bollettino d'arte, 86-87, 1994, 138-196: 194, Documento II Inventario de 1746, San Ildefonso; sobre Neptuno, 144, nota 84, que incluye las referencias dadas. También dio noticia de documentos del Archivo Histórico de Protocolos (A.H.P. Madrid), legajo 9819, escribano Andrés Caltañazor en cuya lectura se encontró la nota sobre la postura del Neptuno. Almoneda, comienza el Inbentario de los bienes que quedaron a la muerte del Marqués del Carpio, año 1688, en f. ${ }^{\circ} 827$, Estatuas del Jardín, se inicia lista con la descripción del Neptuno, tasado, f. ${ }^{\circ} 1070$ v..$^{\circ}$, por el M..$^{\circ}$ Henrriquez y Pedro Alonso de los ríos «:marmolistas»; nota 185: sobre un Inventario de 1692 y la Memoria citada de 1706 en los que se localizó la descripción mencionada del Neptuno de mármol blanco en documentos del Archivo de la Casa de Alba. Ponz, cit. (Ed. Aguilar) vid. 3. Testamentaría de Carlos III cit. en 5: II, Pieza décima de San Ildefonso, 301, n. ${ }^{\circ} 2852$ (el Neptuno antiguo de 8 pies). 
II..el Excmo. Señor D.Gaspar de Haro y Guzman, Marqués del Carpio y de Heliche ordenó que a similitud de la machina que erigio en Plaza Navona el Cavallero Bernini se dispusiese esta con superintendencia del mismo, que haviendo muerto mientras se perfeccionava cerró con este Posthumo parto la fecundidad de su mente. Anno MDCLXXXI, es decir, fechada justo un año después de la muerte del gran artista.

La descripción del Inventario de 1682 habla de las quattro figure de marmo bianco que serían las de los Cuatro Grandes ríos que aparecen en la fuente Navona de Roma y de otras piezas que los acompañaban como las figuras de un caballo, un león, delfines etc. o piezas de diaspro de Sicilia o de pórfido, material en el que se había realizado su guglia o aguja coronada por la figura de la Fama en metal además de un relieve con el retrato del propio Bernini.

El Inventario manuscrito del Escorial del 1683 es más minucioso y en las cajas marcadas con la Letra Y que contenian las piezas integrantes de la Fuente encomendada por el Marqués del Carpio menciona concretamente las figuras del Argenteo o Eufrates, Ganges, Nilo y Danubio y otras figuras de animales que la completaban como el caballo enviado en dos mitades que en la fuente de la plaza romana aparece bajo los escollos. Se piensa que precisamente esta figura confundió a los que describieron la escultura en San Ildefonso pues aunque Ponz la identificara con un río al describirla en Aranjuez el año de 1791, al mencionarla en San Ildefonso años antes, el de 1781, también le dió el nombre de Neptuno, que debió definirse cuando se presentó en la Almoneda ya que todo apunta a que se refiera al mismo conjunto que como se dirá en el estudio estilístico y sugieren los documentos de su envio desde Italia, en Madrid pudo perder su primitiva apariencia. Pudieron conformar el grupo antes de presentarlo en la Almoneda con la figura de uno de los ríos y una de las dos mitades del caballo, la parte superior, que se envian el año de 1683, como se ha dicho en piezas separadas en distintas cajas, como parece indicar el dorso de la figura (fig. 2). Lo que sí extraña es que el ilustre Abate en una y otra cita no recordara las figuras de la Fuente Navona pues en el Alcázar describió la pequeña réplica de la misma Fuente que allí se conserva, ahora redescubierta en Palacio ${ }^{7}$.

En resumen parece que las figuras de la de la Fuente dei Quattro del Molo debieron efectivamente enviarse a la Casa de Campo y que hay que seguir buscándolas y que el río descrito por Ponz es efectivamente el Neptuno citado desde 1746 en San Ildefonso, localizado en Aranjuez el año de 1789; por lo mismo tiene que ser el Neptuno echado procedente de la colección del Marqués del Carpio según se describe en la Almoneda de sus bienes y quizás corresponderse con uno de los ríos de la réplica de la Fuente Navona realizada antes de 1681 bajo la dirección del propio Bernini y enviada a su palacio de Madrid. Se recuerda que como tal Neptuno no se menciona en los Inventarios de la colección Carpio, realizados en Italia antes de su envío a España en los que se mencionan otras muchas esculturas de mármol con sus nombres o símbolos, como la statua di marmo bianco antico con UN VASO IN COLLO che geha l'acqua..., descrita en el de 1682, que presidía la Fuente de los Ánades, posiblemente también deshecha, pues no la mencionan en la Almoneda. No obstante, no debe olvidarse que la figura de Aranjuez identificada como el Dios marino apoya su brazo izquierdo en una urna que vierte agua, símbolo de los ríos, pero su mano derecha aparece sobre un objeto apenas visible que podía ser la cabeza de un tridente.

Las circunstancias de la venta de la colección son conocidas y ello explicaría la fragmentación de este monumento. La, en cierto modo, inesperada muerte del Marqués en Nápoles el

\footnotetext{
Cacciotti, cit. 6: Archivio Casa Alba, Inventario e descrittione delle mobile... del Exc.mo. D.Gaspar de Haro e Guzman. In Roma, 1682. En p. 37 y nota 41: sobre el Álbum de Londres. Rosario Cappel, que ha consultado el documento, ha confirmado que no contiene ningún dibujo que pueda referirse a esta escultura. Inventarios de 1683 y 1687: se conservan manuscritos en la Biblioteca del Monasterio del Escorial, Códice IV, 25 (Lista de cuadros y objetos aristicos remitidos desde Italia a España por el Puerto de Nápoles en los años de 1683 y 1687). Ponz, Ed. Aguilar (1772) 538, Alcázar: Guardajoyas. Esta joya se ha localizado recientemente en Palacio, según me comunicó el Dr. Moya.
}

AEA, LXXV, 2002, 298, pp. 117 a 128 

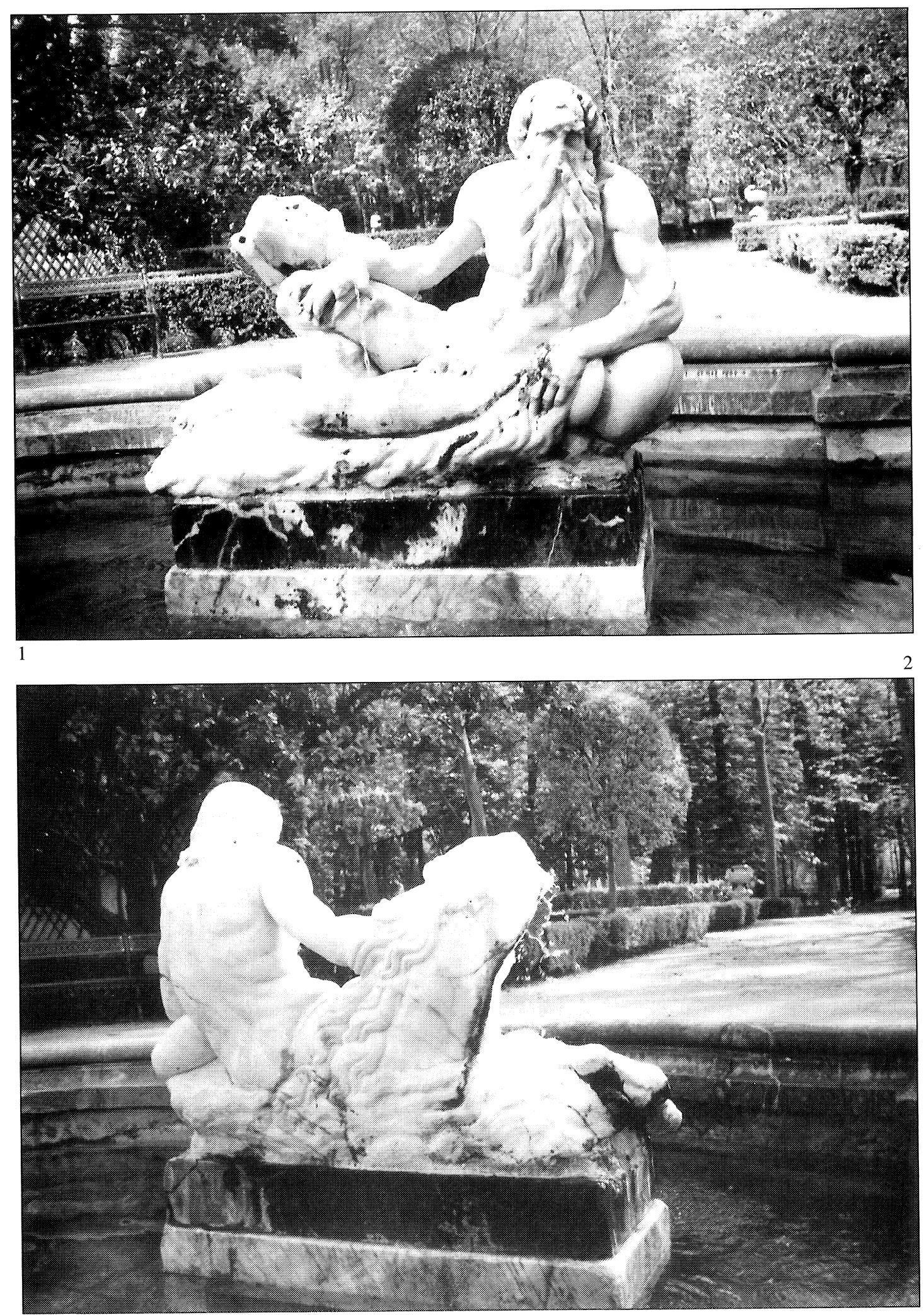

Figs. 1 y 2: Bernini (dirigida por ?): Neptuno (Río?). Aranjuez (Madrid), Jardín del Príncipe.

AEA, LXXV, 2002, 298, pp. 117 a 128 
año de 1687 dejó a la familia en dificil situación económica lo que decidió la venta de los bienes de la colección en Almoneda, ordenada por su heredera, su única hija Catalina, casada con el Duque de Alba.

Según el Inventario redactado en Roma el año de 1682, la réplica de la Fuente Navona era uno de los bienes descritos con más interés como obra dirigida por el propio Bernini, pues aunque no pudo verla acabada, se la considera su obra póstuma. Wittkower habló de una réplica de la Fuente romana localizada en Inglaterra, pero por las fechas de su envio la considera obra tardía.

Como se ha dicho, los Inventarios confirman su envio a España y el redactado en Nápoles el año de 1683 la describe por piezas separadas enviadas en cajas numeradas y señaladas con la letra Y y al menos en cuatro navios diferentes (el Bajel de Santa Rosa trajo 24 elementos, el de San Jerónimo, 10, el de San Diego de Alcalá 17 et.). La descripción de las figuras o elementos que contiene cada caja corresponde muy exactamente a los que conformaban la réplica de la Fuente Navona, descrita en el Inventario de 1682 y en la Introducción al Álbum de dibujos de la colección conservado en Londres. Debió ser bastante fiel al modelo pues repite elementos y figuras de la Fuente de la Plaza Navona de Roma realizada por el Bernini.

La fecha de su llegada a España y la muerte del Marqués a los pocos años sugiere que nunca llegó a montarse lo que parece confirmar el Inventario realizado el año de 1689, previo a la citada Almoneda de los bienes del Marqués del Carpio en el que ya se menciona la figura de un Neptuno echado y no se hace ninguna referencia a la Fuente de la Plaza Navona ni a la de los Ánades, aunque sí se citan algunas otras fuentes como la de la Piña o la conformada por tres Cupidos, que sin embargo no se relaciona en los Inventarios anteriores aunque es extraño que tampoco se mencionen las figuras de los otros ríos.

Se ha advertido además que entre los elementos inventariados en 1689 aparecen muchos que pudieran haber correpondido a esta réplica de la Fuente de la Plaza Navona que se describen en los Inventarios de 1682 y 1683, como la figura de una culebra, leones, aunque de alabastro, piezas de mármol, dos pirámides de mármol rojo — una de ellas quizás la Guglia de pórfido que sostenía la figura de la Fama_, pedestales de jaspe de Sicilia — ¿el diaspro de Sicilia que conformaba su pavimento? - y las armas del Marqués lo que apoya la hipótesis de que la fuente no llegó a instalarse y que incluso algunas de sus figuras se arreglaron en conjuntos parciales, como podría ser la figura de uno de los ríos que aunque lleva la urna de agua que le identifica se transformó en un Neptuno quizás pensando en su mejor venta. También es posible que la familia se reservara alguna pieza lo que explicaría la ausencia en el Inventario, previo a la Almoneda, de las figuras de los otros ríos que tampoco se mencionan en los posteriores citados y sólo puede pensarse que corresponda a alguno de ellos la otra estatua echa pedaços de marmol blanco a la que se alude en la Memoria de 1706. No se vendieron todos los objetos y de hecho la figura del Neptuno sobrevivió a la venta y fue comprada a la Duquesa de Alba por Felipe V incluido en un conjunto de otros varios objetos contenidos en la lista redactada el año de 1746, se corresponda o no con uno de los ríos de la réplica de la Fuente Navona ${ }^{8}$.

\section{La fuente de los Pabellones o de Neptuno, en el Jardín del Príncipe}

Los datos documentales expuestos apuntaban claramente a una escultura procedente de la colección del Marqués del Carpio y eliminaban la posibilidad de que la figura de Aranjuez

\footnotetext{
${ }^{8}$ Cacciotti, cit. 6: 135 y 167-171: La dispersión, y cit. 7: sobre el Album de dibujos. Recoge también cita de Wittkower, Rudolf, Gian Lorenzo Bernini. The sculptor of the roman baroque. London, 1955, cat. 50. Vid. nota 7: Inventarios de El Escorial, f. ${ }^{\circ} 4$ a-5 v. (Cajas que contienen la Fuente Navona, n. 51 y y 43 y, caballo; n. ${ }^{\circ} 73$ a 76 Y, los ríos). Memoria de 1706 vid. 6: f. ${ }^{\circ} 3$ v. ${ }^{\mathrm{a}}$. Sobre el tridente, vid. más adelante.
} 
fuese uno de los ríos realizados por Caccavello y D'Auria para la Fontana dei Quattro del Molo y enviados a España pues además se sabía que éstos sujetaban sus respectivas urnas que vertían agua entre sus piernas y no bajo el brazo como aparece en el de Aranjuez.

Estas noticias se han completado con el estudio de la pieza que por ventura se conserva aún en Aranjuez, donde dio noticia de ella Carmen Añón que dice: En la fuente de Neptuno, llamada también fuente de los Pabellones por estar en el jardín de este nombre, vemos la figura del dios del mar recostada y agrupada con un caballo marino que, según nos cuenta Madoz — tomado de Álvarez de Quindós- «estuvo colocada, formando sus aguas un pequeño arroyo, en un lugar recóndito del jardín del Príncipe y es una de las mejores esculturas que hay en él». Sin olvidar el problema de la figura de Neptuno del Museo del Prado, cuya solución seguramente decidirán los arqueólogos $\mathrm{y}$, dado el resultado negativo de la consulta del Álbum de Londres y la del Álbum Ajello -éste con los dibujos de las obras que en tiempos de Isabel de Farnesio se almacenaron en San Ildefonso-, la investigación llevada a cabo se ha expuesto ahora en síntesis, pues en todo caso se cree suficiente para fundamentar la propuesta de identificación de esta escultura con la de uno de los ríos que compusieron la réplica de la Fontana Navona del Bernini realizada bajo su dirección para el Marqués del Carpio. Su estudio estilístico como se verá aunque no definitivo la apoya con toda la problemática que conlleva y descarta la primera hipótesis sobre su posible identificación con uno de los ríos de la Fuente del Molo napolitana ${ }^{9}$.

La escultura conservada en este lugar podría haber formado parte de esta réplica de la Fuente de la Plaza Navona romana enviada a España por el Marqués del Carpio, según se describe en un texto suplementario al proporcionado por los Inventarios que aparece incluido precisamente en el Albúm de dibujos de su colección conservado en Londres, que literalmente, según transcripción de Beatrice Cacciotti, determinaba que se trataba de una Fontana intiera simile alla gran fontana ..en Piazza Navona. alta quatro palmi piu della terza parte di questa la di qui guglia é di pietra di porfido alta dieci palmi ... a fin che 'a posteri resti l'autentico dell'artefice vi é scolpito a basso rilievo il ritratto del Cavr.Gio Lorenzo Bernini ...sendo questa ultima opera de un tanto virtuoso frases que presuponían la autoría del Bernini. Los escollos que escondían los ríos eran de mármol cotognino y la conca de diaspro en tanto que las estatuas eran de mármol blanco.

La medida facilitaba la identificación por algun dato de Fraschetti sobre la Fuente Navona de Roma por lo que puede pensarse que su tercera parte, de la réplica del Carpio, podía albergar cuatro figuras del tamaño del natural, los ca. 1,60 ms.del río de Aranjuez, instaladas sobre escollos con la aguja coronada por la figura de la Fama. Lo mismo sugieren los tamaños de sus distintas piezas como el del pedestal que medía 4,75 palmos en cuadrado ${ }^{10}$.

A primera vista su contemplación decepciona por el deterioro que presenta. Un primer análisis confirmó los datos documentales pues su estilo denunciaba a un artista barroco y decididamente no encajaba con el quehacer del Caccavello y D'Auria, de figuras mucho más sosegadas, rostros anchos e inexpresivos y anatomías más rudas en composiciones muy equilibradas, de acuerdo a la cronología y escuela en las que se desarrolló su actividad ${ }^{11}$.

\footnotetext{
9 Vid. nota 2: Capasso. Añón, Carmen; Luengo, Mónica, y Luengo, Ana, Jardines artísticos de España. Madrid, Espasa Calpe, 1995, 50.Cacciotti, cit. en 6: sobre el Album Ajello, nota 3 y p. 141; sobre el de Londres, cit. en 7. Elvira Barba, Miguel Ángel: El cuaderno Ajello y las esculturas del Museo del Prado. Madrid, Museo del Prado, 1998-1999.

${ }^{10}$ Cacciotti, cit. 7, Álbum de Londres, nota 64. Fraschetti, Stanislao, Il Bernini. La sua vita, la sua apora, il suo tempo. Milano, 1900, 192.

1 Sobre Caccavello y D'Auria: Venturi, Adolfo, «La scultura del Cinquecento» Storia dell'arte italiana, X, I, Milano, 1937 (reed. en 1967). Abbate, Francesco, «Il sodalizio tra Annibale Caccavello e Gian Domenico d'Auria e una ipotesi per Salvatore Caccavello», Annali della Scuola Normale Superiore di Pisa, 1976, 129-145: estudio muy amplio. Idem, La scultura napoletana del Cinquecento. Roma, 1992.
} 

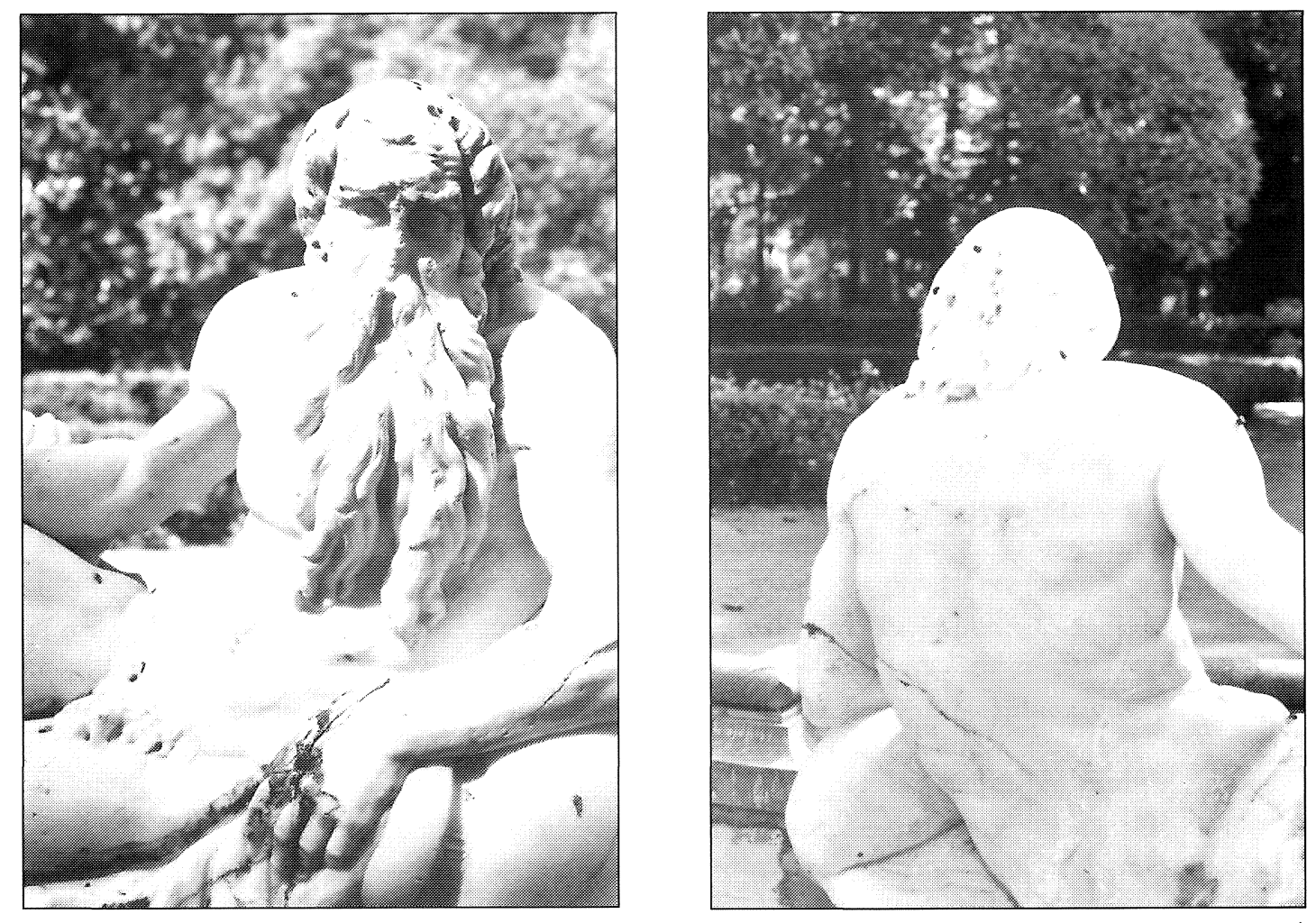

3

5

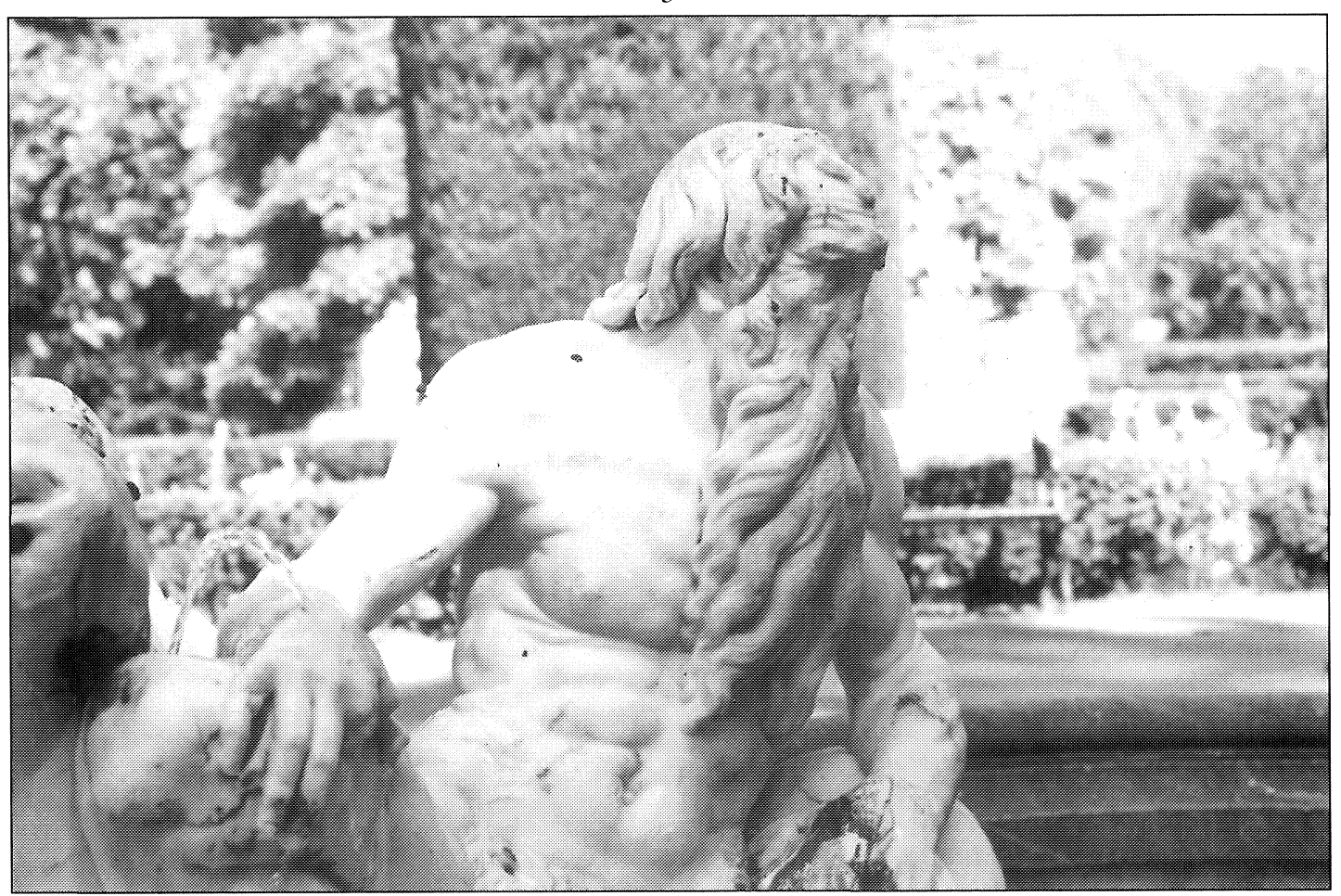

Figs. 3-5. Bernini (dirigida por ?): Neptuno (Río?). Detalles. Aranjuez (Madrid), Jardín del Príncipe.

AEA, LXXV, 2002, 298, pp. 117 a 128 
La figura del llamado Neptuno representa a un hombre viejo, con larga barba, semirrecostado que apoya su brazo izquierdo en una vasija redonda o «urna» que vierte su agua, elemento que determina su iconografía, con una marca en su cuello en forma de $\mathrm{T}$ (fig. 3) incluida en un semicírculo, cuyo significado de momento no conocemos, en tanto que su mano derecha apoya en una especie de rejilla que podía ser una cabeza de tridente en muy bajo relieve, apenas visible, elemento que quizás, con la cabeza de caballo posiblemente añadida, decidió su identificación con Neptuno (fig. 5). No se ha podido aclarar el tema por la erosión del relieve pero hay que recordar que en los Inventarios del Escorial se describe al Ganges con su remo que debería sujetar con esta mano aunque no parece lógico que se confundiera con un tridente, que por otra parte, no es incompatible con la representación de un río, como explicó Marle, que también aclaró que a Neptuno en casos se le representa con la urna de agua. En todo caso, la posición de la mano no parece la más adecuada para sujetar el tridente. La figura presenta orificios para la salida del agua.

Con el torso de frente, de muy bello modelado a lo Bernini, carne flácida de viejo, extiende su pierna izquierda sobre el escollo que le sustenta en tanto que dobla la derecha sobre la que apoya la mano marcando una línea en diagonal subrayada por la cabeza en alto del caballo marino situado a su costado. Ya se sabe que a partir del Renacimiento se imitaron las figuras de los ríos antiguos localizados, hasta nueve en Roma, en su clásica actitud reposada advirtiéndose en este ejemplar, que aún en esta línea, el Barroco le ha marcado con su dinamismo.

El estudio estilístico de la escultura resalta el interés del rostro, aunque ha perdido la nariz. Sus hundidos ojos de pupilas horadadas y bajo arcos supraciliares fuertemente marcados que al decir del Frascheti proporcionan a las figuras del Bernini algo de la terribilitá miguelangelesca y la delicada contextura de su anatomía, con recuerdos de la que define el cuerpo viejo de San Jerónimo de un dibujo autógrafo del gran escultor , quizás lo mejor conservado de la figura, decidieron sin duda el juicio de Ponz que vió en la escultura ecos de la obra de Miguel Angel. Su cabello y sobre todo sus largas barbas que partidas en dos entrelazan sus largos mechones desde su raíz con ciertos recuerdos de otras obras berninescas, como por ejemplo las del Tritón, de su fuente, han sufrido la acción del tiempo y no dejan percibir con claridad su específica factura. Es curioso que en la colección del Marqués del Carpio, de donde parece que procede, se conservara un precioso dibujo de un río por Anniello Falcone, que aunque en posición diferente, con la urna entre las piernas, recuerda su figura ${ }^{12}$.

Sus potentes brazos trabajan los músculos sin exageración y son muy expresivas sus fuertes manos de largos dedos con los nudillos señalados.

$\mathrm{Al}$ dorso suaviza el modelado y se acentúa el ángulo entre su figura y la del caballo marino adosado a su costado (fig. 4). La figura de éste, su mitad superior, aparece aún más deteriorada y apenas se percibe su cabeza, muy levantada, pues ha perdido el morro y sólo se advierten sus ojos saltones. Su actitud simula un movimiento de salto que subrayan las crines cuidadosamente trabajadas, demasiado para una obra berninesca (figs. 1 y 2).

Así pues, desde el punto de vista documental parece claro o al menos muy probable que esta figura de río, por la urna que sujeta bajo el brazo, al que se le llamó Neptuno porque quizás llevaba un tridente y se le emparejó con una cabeza de caballo, ello «a posteriori» como puede observarse al dorso del grupo, procedía de la colección del Marqués del Carpio según la lista de las obras adquiridas por Felipe V de la Duquesa de Alba, aunque no se puede descartar

12 Marle, Raymond, Iconographie de l'art profane au Moyen Age et à la Reanissance. New York, 1971, 2 vols.: II, Cap. IV: los Elementos. Fraschetti, cit. en 10, 192 al describir el Ganges de la Fuente romana de la Plaza Navona destaca su volto fiero... ricordo del Mosé michelangiolesco. Wittkower: Fuente de la Plaza Navona, cat. n. ${ }^{\circ} 50$. Hibbard, Howard, Bernini e il Barocco. Milano, 1965. Avery, Charles, Bernini. Genius of the Baroque. Photographs by David Finn. London, 1997, 193-203; fig. 390 en p. 270 dibujo de San Jerónimo. Cacciotti, cit. en 6, dibujo de Falcone, lám. III a. 
totalmente que en dicha relación se incluyera alguna escultura que no procediera de aquella colección.

Al no aparecer ningún Neptuno en los Inventarios consultados de la colección Carpio realizados en Italia, se pensó que esta figura que sí se menciona en la Almoneda de la colección, echado, podía ser uno de los ríos de la réplica de la Fuente Navona cuya dirección encomienda el Marqués del Carpio al propio Bernini y que sus contemporáneos juzgaron ultima opera del gran escultor.

Los problemas que presenta esta propuesta de identificación son muchos pues desde el punto de vista estilístico, aunque la obra es de gran calidad, presenta recuerdos del Bernini y además por su deterioro no puede analizarse correctamente, no responde exactamente a las mejores obras del gran maestro.

No obstante, hay que recordar que el Bernini sólo se encarga de su dirección y que muere un año antes de terminarse la fuente en 1681 y ser enviada a España en 1683. Tuvo que hacerse por algún artista de su entorno, algo común en muchas de sus obras incluida la de la Fuente romana de la Plaza de Navona cuyos ríos fueron realizados por discípulos aunque fuesen de la categoría de, por ejemplo, el Baratta. Ello exigirá en el futuro un estudio estilístico a fondo incluso para fundamentar su pertenencia al círculo del Bernini, aclarar el detalle del tridente y localizar la marca de la $\mathrm{T}$ incluida en un semicírculo que aparece en la urna.

Más dificultad presenta compaginar la composición del río de Aranjuez con la actitud que adoptan los cuatro ríos de su modelo pues aunque efectivamente responde muy de cerca a la sosegada posición del Ganges, invertida, de la fuente romana, no puede afirmarse que sea su exacta copia y parece, por los documentos, que la réplica se ajustó muy estrictamente a la obra del Bernini.

Los problemas que se han expuesto impiden dar por seguro algo que los documentos indicaban muy claramente, la propuesta enunciada de identificar la figura de río, de Aranjuez, con el Neptuno procedente de la colección Carpio, que podría ser uno de los ríos de la réplica de la fuente de la Plaza Navona cuya dirección se encomienda al Bernini. En todo caso se mantiene con la esperanza que, en su discusión, se aclare definitivamente la filiación artística de esta interesante escultura que, en el peor de los casos, es obra italiana de calidad, muy posiblemente del siglo XVII y con toda probabilidad procedente de la Colección del Marqués del Carpio. 